\title{
Governança pública: novo modelo regulatório para as relações entre Estado, mercado e sociedade?*
}

\author{
Leo Kissler** \\ Francisco G. Heidemann***
}

\section{Introdução}

Após uma década de "modernização do setor público" na Alemanha, é hora de se fazer um balanço sobre a experiência. E constata-se que as administrações públicas se tornaram mais empresariais, menos onerosas e, em geral, mais eficientes; raramente, porém, mais simpáticas aos cidadãos. Em outras palavras, as fronteiras - entre os órgãos públicos e os cidadãos, entre os setores público e privado — de fato receberam novos contornos, com base na privatização e na terceirização; mas as novas bases não se revelaram favoráveis aos cidadãos.

A modernização do Estado que ocorreu nos últimos 10 anos foi, principalmente, uma reforma interna inspirada na administração pública gerencial (new public management). Pautando-se por este modelo ideológico, o Estado voltado para o mercado e para a gestão na prática provocou sobretudo uma redução dos postos de trabalho na administração pública.

\footnotetext{
* Texto-base de uma palestra proferida em out. 2004, em Balneário Camboriú, para os alunos do Curso de Administração de Serviços Públicos da Esag, e, em Florianópolis, para pesquisadores do Centro de Filosofia e Ciências Humanas da UFSC. Tradução do original alemão: Elizabeth Lemcke. Contribuições à tradução: Alessandro Pinzani (UFSC) e Mário L. Rollof (Esag). Revisão técnica (lingüística): Ulf G. Baranow, Decigi/UFPR. Apoio: Sociedade Alemã para a Pesquisa (DFG) e Esag/Udesc.

** Professor of sociology Philipps-University Marburg. Endereço: Ketzerbach, 11 - 35037, Marburg, Germany. E-mail: kissler@staff.uni-marburg.de.

*** Professor do Curso de Graduação em Administração e Serviços Públicos e pesquisador e subcoordenador do Mestrado Profissional em Administração — Esag/Udesc. Endereço: Rua das Manjubas, 446 Jurerê — CEP 88053-422, Florianópolis, SC, Brasil. E-mail: heidex@udesc.br.
} 
Deve-se às condições insatisfatórias da modernização praticada até agora o surgimento e atratividade de um novo modelo: a governança pública (public governance). Até que ponto trata-se de um novo conceito para regular as relações de troca entre os setores público e privado, entre Estado, mercado e sociedade? É particularmente desafiador responder em termos científicos a essa pergunta. $\mathrm{O}$ entendimento que se tem sobre governança pública não é muito claro; Max Weber diria tratar-se de um conceito sociologicamente "amorfo". Não existe um conceito único de governança pública, mas antes uma série de diferentes pontos de partida para uma nova estruturação das relações entre o Estado e suas instituições nos níveis federal, estadual e municipal, por um lado, e as organizações privadas, com e sem fins lucrativos, bem como os atores da sociedade civil (coletivos e individuais), por outro. Pairam dúvidas não somente sobre as bases de cooperação entre esses atores, mas também sobre seus resultados. Diante disso, o campo incerto da governança pública será abordado a partir de três perguntas, que servirão também para estruturar a exposição.

t O que significa governança pública, qual é a imagem de Estado contida nesse conceito e quais são seus objetivos implícitos? Faz-se aqui um esclarecimento teórico-conceitual (primeira parte).

t Como se traduz governança pública, na prática? Existem critérios testados na prática que servem para verificar se a governança pública obteve sucesso ou se fracassou? Essa pergunta será respondida a partir de um exemplo prático extraído da política de emprego e mercado de trabalho no âmbito municipal. Para isso, serão usados os resultados de uma pesquisa de avaliação realizada nos anos 2000-02, em dois grandes centros urbanos da Alemanha.

t E, finalmente, que conseqüências e efeitos colaterais apresenta a nova estruturação de relações entre Estado e sociedade em decorrência da governança pública? Trata-se de um prognóstico e de uma tomada de posição para a indagação final: até que ponto a governança pública será adequada para servir como novo modelo regulatório de Estado e sociedade?

As duas últimas perguntas serão tratadas na segunda parte.

\section{Governança pública: conceituação}

Antes de tudo, o conhecimento do problema é decisivo para a fundamentação teórica da governança pública, para a avaliação da prática vigente e, sobretudo, para uma projeção de sua capacidade de solucionar problemas. Por essa razão, a exposição 
será iniciada invocando-se um pouco de história recente: nos últimos 10 anos, a modernização do setor público alemão não foi um fim em si mesma. Ela continha a promessa de oferecer respostas consistentes para três perguntas centrais, que eram:

t de que modo podem ser conduzidas politicamente as sociedades desenvolvidas, diante dos imperativos de uma economia internacionalizada (globalização e europeização)? Essa pergunta trata da governabilidade de sociedades complexas, funcionalmente diferenciadas;

t de que forma pode-se superar a crise orçamentária das organizações públicas, diante das crescentes pressões dos custos sobre os sistemas de seguridade social e dos elevados custos associados à unificação alemã? Essa pergunta refere-se à capacidade de financiamento do moderno Estado social;

t e, finalmente, como é possível dar conta dos valores emergentes nas sociedades modernas e das novas expectativas dos cidadãos por um Estado eficiente, a partir das novas possibilidades de participação e engajamento dos cidadãos? Essa questão diz respeito à legitimidade da ação estatal.

A atratividade da governança pública reside na expectativa de que ela venha a oferecer respostas conceituais cientificamente fundamentadas para essas perguntas. Ver-se-á até que ponto essa expectativa se sustenta.

\section{O que é governança pública?}

No debate atual sobre a continuidade da modernização do setor público alemão, a governança tornou-se um conceito-chave, que todos utilizam sem saber exatamente o que é. Seu significado original continha um entendimento associado ao debate político-desenvolvimentista, no qual o termo era usado para referir-se a políticas de desenvolvimento que se orientavam por determinados pressupostos sobre elementos estruturais — como gestão, responsabilidades, transparência e legalidade do setor público — considerados necessários ao desenvolvimento de todas as sociedades (pelo menos de acordo com os modelos idealizados por organizações internacionais como a Organização das Nações Unidas [ONU] ou a Organization for European Cooperation and Development [OECD]).

No presente contexto temático, propõe-se entender governança como 
uma nova geração de reformas administrativas e de Estado, que têm como objeto a ação conjunta, levada a efeito de forma eficaz, transparente e compartilhada, pelo Estado, pelas empresas e pela sociedade civil, visando uma solução inovadora dos problemas sociais e criando possibilidades e chances de um desenvolvimento futuro sustentável para todos os participantes.

(Löffer, 2001:212)

Contribuições significativas para a definição de governança também vieram de pesquisas regionais: "Governance, in a first instance, can be simply understood as the structures and the ways in which city regions are 'managed', in an administrative, legal, public, private, local, national and European sense” (Ache, 2000:444). Os atores locais e regionais desenvolvem ação conjunta movidos pela expectativa de que conseguem avaliar melhor os problemas de sua região do que os atores nacionais ou supra-estaduais. As expectativas políticas e sociais geradas pela cooperação entre os agentes regionais são significativamente elevadas, por exemplo, no campo do mercado de trabalho e das políticas de emprego, desenvolvimento municipal, combate à pobreza etc.

Sob a ótica da ciência política, a governança pública está associada a uma mudança na gestão política. Trata-se de uma tendência para se recorrer cada vez mais à autogestão nos campos social, econômico e político, e a uma nova composição de formas de gestão daí decorrentes. Paralelamente à hierarquia e ao mercado, com suas formas de gestão à base de "poder e dinheiro", ao novo modelo somam-se a negociação, a comunicação e a confiança. Aqui a governança é entendida como uma alternativa para a gestão baseada na hierarquia. Em relação à esfera local, ela significa que as cidades fortalecem cada vez mais a cooperação com os cidadãos, as empresas e as entidades sem fins lucrativos na condução de suas ações. A cooperação engloba tanto o trabalho conjunto de atores públicos, comunitários e privados, quanto também novas formas de transferência de serviços para grupos privados e comunitários. A governança local, como configuração regional da governança pública, é, assim, "uma forma autônoma (self-organizing) de coordenação e cooperação, por meio de redes interorganizacionais, que podem ser formadas por representantes de organizações políticas e administrativas, associações, empresas e sociedades civis, com ou sem a participação estatal" (Jann, 2003:449).

O teor normativo do conceito é marcante na discussão sobre governança pública na Alemanha. Além da análise das estruturas e dos processos de governança, busca-se resposta para a questão dos seus objetivos maiores. Assim, por exemplo, define-se a governança local "como uma ação conjunta via rede de todos os 
stakeholders (grupos de cidadãos, administração, prefeituras, associações tradicionais, clubes, empresas), em prol do bem da coletividade" (Damkowski e Rösener, 2003:73, grifo nosso); a governança pública faz, assim, da orientação para o bem comum o diferencial entre a simples governança e a boa governança.

Os fundamentos normativos da governança pública se estabelecem por um novo entendimento do Estado como agente de governança. Em outras palavras, eles resultam da resposta à pergunta: que significado tem o Estado nas estruturas de governança? Ou, dito de outra forma: o que distingue governança de governo?

A resposta a essa pergunta permite identificar três fases no debate sobre a transição do Estado convencional para um novo modelo de Estado. Assim, conceitualmente, o Estado tradicional vem se transformando:

t de um Estado de serviço, produtor do bem público, em um Estado que serve de garantia à produção do bem público;

t de um Estado ativo, provedor solitário do bem público, em um Estado ativador, que aciona e coordena outros atores a produzir com ele;

t de um Estado dirigente ou gestor em um Estado cooperativo, que produz o bem público em conjunto com outros atores.

Cada uma dessas três dimensões refere-se a diferentes etapas na história das reformas alemãs e a uma superação gradual da idéia tradicional, segundo a qual o Estado seria o guardião e protetor do bem comum. No entanto, o modelo de mercado radical — segundo o qual a mão invisível do mercado asseguraria o bem comum, independentemente da ação regulatória do Estado — está igualmente obsoleto. Na verdade, os dois modelos estão historicamente ultrapassados. Eles estão impregnados de uma contraposição entre Estado e sociedade, pela qual se reconhece o Estado apenas como uma forte instância de planejamento e gestão, por um lado, ou como um "Estado guardião", por outro. Em qualquer das hipóteses, o Estado é entendido apenas como um ente que dirige ou atrapalha o desenvolvimento social.

Sobre a transição do Estado provedor para o Estado garantidor da produção dos serviços públicos, há um debate político que trata da amplitude das atividades estatais. Na Alemanha, a discussão internacional sobre a gestão pública lançou as bases para essa política de amplitude da atuação estatal. Ela funciona de acordo com os seguintes parâmetros (ver figura): o dilema entre "produzir ou comprar" é respondido a partir da relevância estratégica de um serviço e da especificidade dos recursos. 
Com base nesses dois parâmetros, os serviços de alta relevância estratégica e alta especificidade de recursos são de atribuição exclusiva do Estado. Em contrapartida, os serviços de baixa relevância estratégica e baixa especificidade de recursos são produzidos por organizações privadas. A discussão sobre modernização abrange em essência os serviços de pouca relevância estratégica, mas que exigem elevada especificidade de recursos.

Relação entre especificidade, importância estratégica e amplitude da atuação estatal

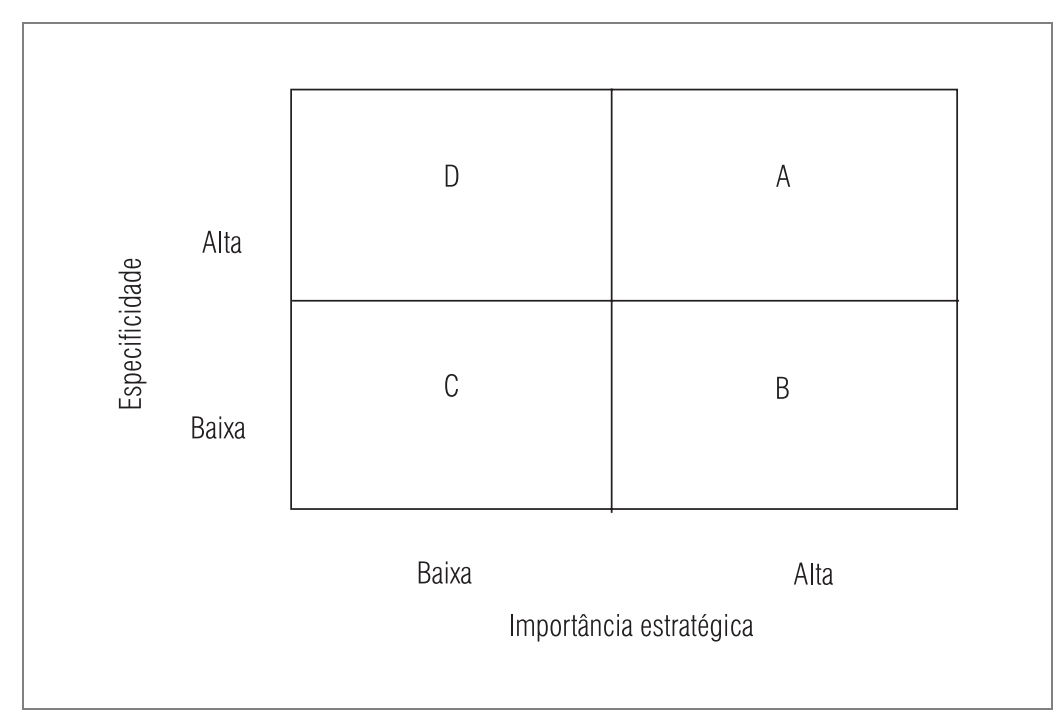

Fonte: Naschold et al., 1996:76.

Assim, pela redução da especificidade dos recursos (ver figura), torna-se possível a terceirização ou a prestação conjunta dos serviços por organizações públicas e privadas. Nesse caso também são questionados os serviços que são estrategicamente relevantes, mas que, sob a ótica da especificidade dos recursos, poderiam igualmente ser prestados pelo setor privado (por exemplo, ciência e educação). Conseqüentemente, o conceito de governança pública justifica uma política de amplitude de atribuições, onde as instituições públicas não têm mais a obrigação de oferecer em termos exclusivos todos os serviços públicos. O Estado pode transferir ações para o setor privado, ou agir em parceria com agentes sociais. Transforma-se, assim, o antigo Estado de serviço em um moderno Estado co-produtor do bem público, mas ainda na condição de responsável último por sua produção. 
O Estado produtor de serviços públicos é um Estado ativo. Ele se caracteriza por um setor público altamente diferenciado e superdimensionado. A ele se contrapõem um setor privado e um assim chamado terceiro setor. Esse "modelo alemão de três setores” obedece a diferentes lógicas de gestão, respectivamente: controle hierárquico no setor público, concorrência no setor privado e solidariedade/negociação no terceiro setor (grupos de auto-ajuda, iniciativas comunitárias, associações, cooperativas, grupos de interesse organizados).

Numa estrutura de governança pública, o Estado ativo, nos termos do modelo dos três setores, se transforma num Estado ativador, que age, principalmente, sobre o setor privado e o terceiro setor, com o propósito de mobilizar seus recursos e ativar as forças da sociedade civil (por exemplo, por meio do engajamento comunitário ver quadro). Isso significa que o setor privado e o terceiro setor acabam sendo valorizados perante o setor público.

\section{Modelo dos três setores}

\begin{tabular}{|c|c|c|}
\hline Setor público & Setor privado & Terceiro setor \\
\hline $\begin{array}{l}\text { Administração direta federal, } \\
\text { estadual e municipal }\end{array}$ & $\begin{array}{l}\text { Mercado de concorrência } \\
\text { pura }\end{array}$ & $\begin{array}{l}\text { Organizações próprias } \\
\text { (grupos de auto-ajuda e } \\
\text { iniciativas comunitárias) }\end{array}$ \\
\hline $\begin{array}{l}\text { Administração própria } \\
\text { (por exemplo, câmaras, } \\
\text { universidades, seguridade } \\
\text { social, IHK)* }\end{array}$ & $\begin{array}{l}\text { Mercado de concorrência } \\
\text { regulada (por exemplo, } \\
\text { o setor de energia) }\end{array}$ & $\begin{array}{l}\text { Associações (sociedades, clubes, } \\
\text { associações de bem-estar social, } \\
\text { cooperativas) }\end{array}$ \\
\hline $\begin{array}{l}\text { Entidades administrativas de } \\
\text { direito privado (por exemplo, } \\
\text { DFG,** GTZ,*** Instituto } \\
\text { Goethe) }\end{array}$ & & $\begin{array}{l}\text { Interesses organizados } \\
\text { (associações, ações conjuntas) }\end{array}$ \\
\hline
\end{tabular}

O Estado deixa de ser uma instituição que se diferencia de forma clara e distinta do mercado e da sociedade, como acontecia no caso do governo tradicional. Estado, mercado, redes sociais e comunidades constituem mecanismos institucionais de regulamentação, que se articulam em diferentes composições ou arranjos. Por isso, a gov- 
ernança prescreve uma lógica de gestão tanto para uma organização quanto para um setor e é usada como conceito-chave para vários tipos de atividades coordenadas. Na verdade, determinadas formas de governança ainda são típicas para certos campos de atuação, como, por exemplo, a hierarquia para o Estado e o mercado para a iniciativa privada. Mas estudos empíricos demonstram que, no ínterim, surgiram arranjos institucionais nos quais transparece um mix de governança. Esse mix caracteriza-se por estruturas mistas, ou híbridas, em que atuam diferentes mecanismos de gestão (controle hierárquico, concorrência, confiança e solidariedade). Seguindo essa tese, as formas coletivas de atuação na sociedade podem ser melhor compreendidas dessa forma do que pelo conceito tradicional de Estado ou pelo conceito de sistema de governo. Para essa perspectiva, é decisiva a transição do Estado gestor (hierárquico), com ingerência na sociedade, para o Estado cooperativo, que atua em conjunto com a sociedade e as organizações empresariais, por meio de parcerias estratégicas.

Em termos de um denominador comum, em suma, a governança pública agrupa, em novos arranjos de atores (redes, alianças etc.), três diferentes lógicas: a do Estado (hierarquia), a do mercado (concorrência) e a da sociedade civil (comunicação e confiança).

Mas esta convergência tem um preço, a saber: a economicização ou mercadização do setor público, ou seja, a transformação do setor público em um empreendimento econômico. Na Alemanha, isso se manifesta pelas seguintes tendências empíricas:

t gerencialização da administração pública (public management), em processo de implantação pela introdução de um novo modelo de gestão (NMG);

t privatização/terceirização/parcerias público-privadas (PPPs);

t concorrência entre organizações públicas e privadas, mas também dentro do setor público.

A seguir são apresentados alguns fatos que ilustram essa megatendência de “economicização” do setor público na Alemanha (Bogumil, 2004).

Implantação de um novo modelo de gestão (NMG), sobretudo nas administrações municipais: no final dos anos 1990, aproximadamente a metade das administrações municipais havia passado da gestão por recursos para a gestão por resultados. Na prática, procurou-se implantar um orçamento doméstico voltado para resultados, com base na ciência das finanças públicas (“cameralística”). Essa tendência, evidente- 
mente, vem regredindo. Entre 1998 e 2000, a ênfase das administrações municipais sobre a abordagem de resultados caiu de $61 \%$ para $32 \%$.

Em contraposição, tornou-se particularmente popular o uso do orçamento, ou a orçamentação. Em 1998, a adoção dessa fórmula já chegava a 88\%. Em 2/3 desses casos, as comunidades voltaram a empregar os procedimentos orçamentários tradicionais, em ampla sintonia com o princípio das finanças públicas.

Entre as concepções administrativas do novo modelo de gestão, o cálculo dos custos dos serviços foi o que mais avançou como componente de controle operacional. No final da década de 1990, 75\% das cidades do leste alemão e mais de $80 \%$ das do oeste estavam ocupadas com a estruturação de alguma forma de controle. No entanto, sua implementação ainda está longe de completar-se. Em 2000, somente 18 dos 206 municípios pesquisados haviam efetivamente adotado a apuração dos custos dos serviços.

Em contrapartida, a mudança para o novo modelo de gestão — pela implantação da gestão por contrato e conseqüente reorganização das relações entre política e administração - revela grandes falhas. Estão igualmente pouco desenvolvidos os métodos de controle político e estratégico. Em particular, a modernização da administração pública, seguindo os preceitos do novo modelo de gestão (NMG), até agora não modificou a estrutura das relações de trabalho dos empregados.

Em resumo, as administrações públicas se tornaram mais eficientes. Por enquanto, porém, não houve “dividendos da reforma” para os servidores. Além disso, o NMG pouco melhorou a capacidade política de administrar as comunidades municipais. O enfraquecido poder político de negociação dos representantes eleitos (isto é, da Câmara Municipal) em relação ao Executivo acentuou-se ainda mais. A governabilidade da cidade continua sendo questionada.

A privatização e a terceirização dos serviços públicos avançaram muito nas comunidades municipais alemãs. Ocorreram grandes mudanças, especialmente nos setores de abastecimento de água e energia, coleta de lixo, bem como no transporte coletivo de passageiros dentro das cidades - todos serviços que já eram responsabilidade do poder público desde o século XIX, na Alemanha. Pressões por mudanças provêm, em grande parte, também, das diretrizes da União Européia, que preceituam a liberalização dos mercados. Mas as mudanças têm origem, igualmente, na crise do orçamento público e na esperança de que, por intermédio da privatização, se consiga superar as deficiências domésticas. 
A liberalização do mercado de energia é a que mais avançou. Mas esse mercado também é um bom exemplo de como a política de liberalização não leva, necessariamente, a uma maior concorrência. Atualmente, o mercado alemão de energia, em virtude de uma concentração empresarial, é monopolizado por apenas dois grandes conglomerados de empresas (duopólio).

Em geral, verifica-se uma tendência para favorecer as forças de mercado, mas um quadro bastante diferente emerge na práxis da liberalização e da privatização. A ampla abertura de mercado para as redes de prestação de serviços e a constituição de empresas privadas em substituição aos prestadores públicos não significa, automaticamente, que o Estado está abrindo mão de sua responsabilidade. Deve-se pensar, também, em novas formas regulatórias, num novo arranjo institucional entre Estado, mercado e participações societárias, que dê fundamento à governança pública. Na prática, porém, tem-se demonstrado que, em muitos casos, as administrações públicas ainda não são capazes de substituir sua ação de produtores do bem público por uma ação de agentes responsáveis pela produção, em cooperação com outros atores. Em muitos casos, faltam para isso instrumentos de uma "gestão estratégica". Isso transparece, sobretudo, nas grandes cidades, que, por enquanto, organizam suas administrações e serviços na forma de empresas municipais. Uma análise da privatização nesses arranjos empresariais, em 36 grandes cidades, no ano de 2001, mostrou que existem ao todo mais de 3 mil participações municipais. Entre elas figuram 334 parceiros públicos oriundos dos níveis não-municipais (isto é, estaduais e federais) e 178 estrangeiros. As participações já consomem mais de 90,5\% do orçamento municipal. Em média, cada cidade conta com um número de 89,2 parceiros para a prestação dos serviços municipais. Com base apenas nesses números, fica evidente onde reside o problema: os representantes eleitos dos municípios têm poucas chances de exercer algum controle. $\mathrm{O}$ número excessivo de parcerias municipais não é mais administrável. Diante disso, também já não se consegue mais orientar os serviços municipais pelo foco do bem público. As participações estão com as "rédeas soltas”. E isso deixa a democracia municipal com as mãos atadas. Como conseqüência, as privatizações e as terceirizações da prestação dos serviços municipais prejudicam, em termos de gestão, os que foram eleitos para participar na tomada de decisões. Isso ocorre por dois motivos. Em primeiro lugar, porque em apenas 1/ 5 das participações existem possibilidades reais de gestão (92\% delas estão constituídas juridicamente sob a forma de empresas de responsabilidade limitada e sociedades anônimas). Em segundo lugar, a situação é agravada pela complexidade que decorre da falta de transparência nas relações entre as sociedades de capital e os órgãos de governo. Os municípios ainda não dispõem de meios suficientes para uma gestão participativa. 
Nos municípios, a onda de parcerias público-privadas (PPPs) é uma tendência cada vez mais forte. Em 2002, mais da metade das cidades alemãs conduzia projetos de PPPs, especialmente nos setores de desenvolvimento urbano, melhoria da infra-estrutura técnica, abastecimento de água e energia e tratamento de efluentes.

O aumento quantitativo de PPPs ainda não permite fazer afirmações sobre a dimensão e a qualidade dos trabalhos realizados de modo cooperativo. Em particular, a capacidade de prestar serviço e as limitações desse tipo de arranjo entre parceiros públicos e privados ainda foram pouco estudadas. A esse respeito, seria muito importante avaliar em que medida as PPPs estão lançando as bases para a continuidade das parcerias estratégicas, sob a égide da governança pública.

A concorrência serve para intensificar de forma decisiva a implantação do novo modelo de gestão (NMG). Na prática, pode-se distinguir duas modalidades básicas de concorrência: as virtuais (formas de concorrência não-comerciais, por meio da comparação do desempenho, benchmarking e concorrência qualitativa) e as reais (concorrências públicas, criação de semimercados [Quasimarkt], assim como a subcontratação externa, ou o retorno à subcontratação interna). Na Alemanha, predominam as formas de concorrência não-comerciais e aí a comparação entre os desempenhos alcançados pelos municípios. Em 2002, 748 municípios participaram em todo o país de 73 rankings comparativos - financiados, principalmente, pela Central de Municípios (Kommunale Gemeninschaftsstelle - KGst) e pela Fundação Bertelsmann, e em parte subsidiados pelos governos estaduais (por exemplo, da Saxônia, Baixa-Saxônia, Baden-Württemberg e Renânia-Vesfália).

Na verdade, porém, as cidades já não estão muito interessadas em manter por um período longo a comparação intermunicipal de desempenho, sobretudo porque até agora ela não tem se mostrado uma solução eficaz para se alcançar uma maior concorrência, o que se deve particularmente à falta de transparência dos resultados. Na maioria dos casos, os resultados repousam no âmbito "não-público" da gestão. Até hoje não existe, no setor público, uma entidade semelhante à Warentest, uma fundação que compara produtos e serviços de organizações privadas e torna públicos seus resultados. A falta de transparência dos resultados enfraquece, assim, a motivação pelo benchmarking. Cerca de $2 \%$ apenas das cidades alemãs ainda cotejam em algum momento os desempenhos obtidos na prestação dos serviços.

Comparativamente aos EUA, Grã-Bretanha e Nova Zelândia, as estratégias alemãs de concorrência municipal estão pouco definidas. Na Alemanha, a concorrência entre prestadores públicos e privados de serviços públicos é em grande parte proibida por lei. Assim, por exemplo, um órgão de serviço público está impedido de participar de concorrências públicas. Em regra, de acordo com os ordenamentos mu- 
nicipais, somente é permitida uma atividade empresarial aos municípios, em três situações, a saber: quando se trata de um interesse público urgente; quando esta atividade não excede a capacidade municipal de prestar serviço; e quando o serviço em questão não puder ser igualmente provido por terceiros. A atuação empresarial do poder municipal fica também restrita à sua área jurisdicional.

Cabe, com efeito, destacar que há uma crescente orientação em favor da concorrência entre os atores independentes sem fins lucrativos. Mas também aí surgem os riscos da concorrência. A disputa entre eles não se transforma, automaticamente, numa concorrência entre serviços e não beneficia a todos os "clientes" de forma igual. Os prestadores escolhem o filé mignon (por exemplo, o atendimento ambulatorial a idosos), e limitam sua atuação a "casos leves", enquanto aos municípios resta atender os casos graves.

As experiências internacionais um tanto negativas de concorrência (por exemplo, o compulsory competitive tendering, de 1980-97, na Grã-Bretanha) reforçam a tendência de se evitar a concorrência na Alemanha. Critica-se, sobretudo, que a "mercantilização" aumentaria a intensidade do trabalho nos órgãos municipais e que, de modo geral, as condições de trabalho do setor público, por ora ainda superiores, nivelar-se-iam às do setor privado, que são piores.

Em suma, a "economicização" do setor público alemão é uma megatendência. Ela baseia-se na implantação de um novo modelo de gestão (NMG), na privatização e terceirização, nos projetos de PPPs e, ainda que de forma restrita, na semiconcorrência (especialmente benchmarking). Por essa razão, são apresentados os fundamentos para uma nova composição das formas políticas de gestão que favoreçam um novo mix de governança. No entanto, até agora essa composição não está suficientemente caracterizada por novas formas sociais, políticas ou econômicas de autogestão, e tampouco está aprimorando a gestão política. O avanço da racionalidade de custos não otimizou os processos políticos de decisão, mas criou as bases para novas formas de cooperação entre atores públicos e privados.

A "economicização" do setor público, em nosso entendimento, fortalece a perspectiva da governança pública e estimula novos arranjos institucionais entre atores estatais e sociais. Sobretudo, ela demarca espaços para se testar a cooperação e parcerias estratégicas em diferentes campos políticos. Considerando-se o desemprego em massa, isso envolve principalmente as políticas municipais de trabalho e emprego. É por isso que esta questão foi escolhida para o estudo de caso.

3. Governança pública: prática e perspectivas 


\section{Como se realiza na prática a governança pública?}

(Pactos municipais de trabalho como campos de governança)

A partir do exemplo dos pactos municipais pelo trabalho, pode-se demonstrar o quanto é promissor, mas também repleto de obstáculos, o caminho para uma governança pública digna desse nome. Por essa razão, a política municipal de trabalho e emprego é adequada para se avaliar as estruturas de governança pública, porque ela oferece um novo campo político para as cidades alemãs. A política de trabalho e emprego é atribuição tradicional da União, e não das cidades. Mas as cidades há muito tempo têm sido as principais empregadoras, implementando os programas nacionais de emprego. Acima de tudo, elas precisam superar as conseqüências do desemprego em massa (elas financiam a ajuda social para evitar o empobrecimento dos que ficam sem emprego por períodos longos).

Em conjunto com outros atores da política, sociedade civil e sindicatos, os municípios vêm testando, nos últimos anos, novas formas de criar redes políticas, como os pactos municipais de trabalho, por exemplo. Essas formas situam-se em uma das pontas de um amplo espectro de redes sociais (networks), alianças e parcerias, nas esferas local e regional, servindo como matéria-prima para o surgimento da governança pública. Sua conjuntura atual na Alemanha é uma resposta às estruturas e organizações sociais ultrapassadas, que já não têm mais condições de enfrentar as crises econômicas e sociopolíticas e, em especial, o desemprego em massa. As alianças municipais de trabalho têm como meta criar novos postos de trabalho e assegurar as vagas nas reformulações da administração pública e dos serviços municipais. Elas unem contratualmente os tradicionais parceiros sociais (associações de empregadores, sindicatos e Estado) em parcerias estratégicas.

Esse tipo de aliança na esfera municipal tem uma longa tradição na Alemanha. Ela remonta aos anos 1960, quando, no âmbito federal, o governo, os sindicatos e as associações trabalhistas decidiram, em conjunto, formular uma política estatal de tributação e distribuição de recursos, inspirada no modelo keynesiano. No nível dos Estados, inúmeros “pacotes de emergência” e “alianças para a modernização” foram tentados, desde então, para empreender uma mudança radical da sociedade industrial para uma sociedade de serviço. Em toda a Europa, com exceção da Grã-Bretanha e da França, existem inúmeras formas de “diálogo social” e de cooperação entre parceiros sociais. Trata-se, a exemplo dos pactos municipais de trabalho, de "arranjos tripartites”, ou seja, o número dos atores é restrito às organizações do setor público, aos sindicatos e aos empregadores. 
Na outra ponta do espectro, visualizamos redes sociais que ampliam seu raio de ação, incluindo, por exemplo, empresas privadas, mas também organizações sem fins lucrativos do terceiro setor e, no âmbito municipal, associações comunitárias e cidadãos individuais. É assim que a concepção de governança pública e o novo modelo de modernização da "comunidade de cidadãos” caminham lado a lado.

As experiências práticas e os resultados científicos, obtidos até o presente, sobre o funcionamento das redes locais e parcerias, coincidem em vários aspectos com os resultados de nossa avaliação sobre os "pactos municipais de trabalho". Os resultados empíricos mostram que:

t as concepções de governança pública são pautadas por um enfoque pluralista. Embora, na prática, a maioria das parcerias entre agentes corporativos seja comandada pelo "arranjo tripartite", constituindo, por assim dizer, um negócio mais ou menos fechado, esse arranjo em princípio encontra-se aberto para outros participantes;

t as alianças e redes sociais podem ser entendidas como um novo modelo político, que se situa entre os extremos da regulação político-administrativa autônoma e da auto-regulação pura de mercado. Todavia, nessas novas relações políticas, os interesses da sociedade civil ainda estão claramente sub-representados;

t nessas estruturas de governança pública, as relações de trabalho repousam sobre consenso e cooperação. O processo de criação de consenso é penoso e frágil, porque, ao contrário da negociação, não repousa sobre um equilíbrio de forças, mas sobre "armas de luta iguais" (mesmo para atores politicamente desiguais);

t as alianças locais e as redes sociais podem ser entendidas como um negócio de troca. Vale o princípio da reciprocidade, subentendendo-se que cada parceiro, no curso de uma compensação de interesses, pode almejar um ganho pela cooperação;

t o acordo é um dos principais pressupostos para uma cooperação entre aliados. A governança pública deve ser aprovada e aceita tanto pelos novos atores participantes quanto pelas respectivas organizações (por exemplo, a administração, os sindicatos de empregados e os sindicatos patronais). Somente dessa forma se consegue alcançar o poder necessário (empowerment) para realizar as atividades e os objetivos das alianças. As alianças sobrevivem principalmente mediante a confiança mútua entre os parceiros. Ninguém deve sentir-se explorado ou enganado. Uma cultura de confiança não se cria por si só; ela resulta de longos anos de desenvolvimento de confiança e de um processo de aprendizagem entre os participantes; 
as alianças precisam de condução, ou coordenação. Deve-se trabalhar de forma permanente o processo de discussão, comunicação e troca entre os atores. Para isso não existe receita certa. É indispensável que os participantes tenham disposição para um autocomprometimento, no sentido de se manterem fiéis às decisões tomadas em bloco;

t as relações de cooperação estão sujeitas a um controle do bom desempenho, isto é, a uma avaliação. Essa é uma condição para que as falhas sejam detectadas e corrigidas em tempo hábil. Mas é, principalmente, pela avaliação que se pode conhecer, não somente os resultados planejados por meio das políticas de aliança e cooperação, como também seus efeitos colaterais não planejados. Entre eles se incluem, sobretudo, os efeitos produzidos pelas alianças municipais e pelas redes sociais sobre a democracia e, assim, sobre o questionamento inicial: até que ponto a governança pública contribui para a governabilidade das entidades municipais, para a viabilidade financeira dos serviços prestados à comunidade e para a legitimidade das decisões tomadas em parceria?

A esse respeito, seguem algumas considerações finais.

Quais problemas são resolvidos pela governança pública? E quais não são?

Avaliações científicas sólidas sobre os resultados da governança pública ainda são raras. A partir dos levantamentos sobre os "pactos municipais para o trabalho” e outras modalidades de cooperação estratégica entre diferentes atores, torna-se possível arriscar um primeiro prognóstico a respeito dos resultados, mas também apontar os problemas de governança não resolvidos no âmbito municipal. Considerando-se que o "ambiente da pesquisa” foi pouco transparente e continha inúmeras lacunas, apresentamos, a seguir, apenas impressões isoladas, que precisam ser sistematizadas e corroboradas posteriormente para representar um quadro completo. Vamos nos ater a resultados empíricos para responder às três perguntas a seguir, cujas respostas dão indicações sobre as condições de sucesso, mas também sobre os obstáculos que intervêm na trajetória de uma governança pública possível.

1. O que faz com que atores, movidos por diferentes interesses e racionalidades de ação, se envolvam em arranjos de governança pública?

2. Como se pode criar alianças, redes sociais e outras formas estáveis e duradouras de cooperação? Em outras palavras, de que modo trabalhos pontuais de cooperação podem ser transformados em arranjos permanentes de governança pública? 
3. E que outros efeitos não previstos podem surgir ou onde termina a capacidade da governança pública de solucionar problemas? Isto é, que problemas são criados ou agravados por seu intermédio?

As respostas indicam que as condições para a cooperação entre os diferentes atores nas estruturas de governança pública se baseiam em pressupostos e conseqüências incertos.

Resposta da 1를 pergunta. Entre os pressupostos da cooperação está o fato de que, na esfera municipal, não se lida com atores homogêneos. $\mathrm{O}$ ator político está sujeito a uma divisão interna entre uma maioria que exerce poder político e uma minoria oposicionista. A gestão é caracterizada, verticalmente, por grupos que se diferenciam por níveis hierárquicos e, horizontalmente, por grupos com interesses homogêneos. Para esses dois atores importa que seu estatuto interno seja aplicável, pois isso é decisivo para que as relações de cooperação com outros entes municipais e regionais tenham chance de sucesso. O êxito da governança pública depende da habilidade estratégica dos atores participantes e da resposta à pergunta: até que ponto pode-se garantir, em relação a uma perspectiva de longo prazo, um estado de cooperação entre atores racionais (como, por exemplo, a administração municipal, a administração do trabalho, os sindicatos, as empresas, associações de assistência social, igrejas, iniciativas comunitárias etc.), que têm interesses próprios e racionalidades de ação específicas? A habilidade estratégica depende do quanto se pode dar conta do problema da racionalidade, o que envolve uma dimensão material (objetiva), uma social e uma temporal. Quanto à dimensão social, pergunta-se que estímulos de cooperação animam atores com diferentes interesses. Que condições os levam a renunciar voluntariamente à autonomia decisória? A resposta, apesar dos distintos interesses e racionalidades de ação, poderia residir em valores compartilhados. Mas é mais provável que os diferentes atores cooperem em função das expectativas de ganho, bem como da pressão por cooperação que advém da complexidade dos problemas. Em vista disso, cresce o entendimento de que cada um dos atores, isoladamente, sentir-se-ia impotente diante do problema, e somente o trabalho em conjunto dar-lhe-ia a chance de resolvê-lo com sucesso.

No sistema alemão de relações de trabalho, observa-se um estilo político favorável à cooperação, que, por sua vez, é favorecida pelo fato de que os atores participantes, em geral, se confrontam em diferentes arenas, como ocorre, por exemplo, na reforma administrativa municipal, na política de tarifas etc. Verifica-se que a cooperação, por um lado, produz ação e, por outro, desenvolve a confiança necessária, na medida em que reduz a incerteza, gerada pelas diferenças de interesses, sobre o comportamento dos outros atores. Por isso, os pactos municipais em prol do trabalho e as estratégias políticas conjuntas sobre mercado de trabalho e emprego 
fortalecem arranjos institucionais entre os atores, o que permite trazer estabilidade às relações entre eles e, com isso, romper a estrutura circular do desenvolvimento de confiança. O desenvolvimento da confiança é circular porque a confiança é não apenas o resultado desejado da cooperação, mas também seu pressuposto.

A capacidade estratégica decorrente do desenvolvimento de confiança pode, também, ser ilustrada com uma analogia. As redes de atores são feitas de fios e nós. Assim, os fios representam as expectativas, objetivos e demandas em relação à atuação dos atores, e os nós representam os próprios atores e suas ações conjuntas. Juntos, eles constituem a estrutura de uma rede. A rede tem a função de reunir atores com interesses parcialmente diferenciados e parcialmente conflitantes, viabilizando seu trabalho conjunto. Os atores estão presos à rede, ou seja, não podem agir de acordo com seus interesses particulares tanto quanto talvez gostariam. Devem sujeitar-se aos processos de negociação, aceitar os resultados negociados e ajustar-se uns aos outros. Ao compreendermos por que isso ocorre, saberemos por que e de que forma surgem as redes sociais e as alianças e o que assegura sua sobrevivência.

Diante do exposto, vislumbro a seguinte perspectiva de resposta: as redes protegem os atores. Isso quer dizer que elas possibilitam aos atores a resolução de problemas que representariam uma carga excessiva para um ator isolado, único. Em outras palavras: quem trabalha sozinho sucumbe. As redes evitam a queda; possibilitam a solução dos problemas, acima de tudo, pela ação conjunta. Sua estabilidade resulta, assim, da pressão por cooperação e do bom êxito da cooperação.

Resposta da $2^{\underline{a}}$ pergunta. Se a capacidade estratégica dos atores depende da cooperação ensejada pelas relações que eles desenvolvem e mantêm como membros de uma rede, surge a pergunta: o que assegura a continuidade dessa rede e, com isso, a estabilidade da governança pública? Parece que o equilíbrio está entre reunir e integrar os atores e evitar seu insucesso, entre, portanto, a delimitação e a viabilização das ações possibilitadas pela elasticidade da rede política.

A elasticidade torna as redes políticas distintas das alianças municipais. As alianças, muitas vezes, são pactos de objetivos, com elevado grau de compromisso e institucionalização. Os atores participantes limitam-se a poucos membros e, com freqüência, atuam em arranjos tripartites. Detêm mais poder, mas também têm menos elasticidade. Em contrapartida, as redes ampliam os grupos de atores e criam espaços políticos intermunicipais, como bases abrangentes e multiopcionais para novas formas de ação cooperativa. Elas abrem caminho para coalizões regionais de desenvolvimento e para uma governança regional em diferentes campos políticos. Com isso, amplia-se a estratégia dos atores, do âmbito municipal para o regional. 
Entretanto, também existe na Alemanha uma série de exemplos de governança regional. Alimenta-se aí a expectativa de que a cooperação nas estruturas regionais de governança eleve a capacidade estratégica e política dos atores e contribua para que as regiões que transcendem as fronteiras de Estados possam vir a ser "governadas" com mais sucesso. Por enquanto fica em aberto se essas expectativas são realistas ou não, pois ainda não se conhecem as limitações de capacidade da governança pública para resolver problemas e também se ignoram seus efeitos negativos imprevistos. Essas questões fazem parte da resposta à próxima pergunta.

Resposta da $3^{\mathrm{a}}$ pergunta. Assim, por exemplo, a capacidade da governança pública para resolver problemas é limitada por cinco fatores.

t Fusão das estruturas de governança e dos ciclos político-parlamentares. O ator político é eleito para um determinado período e sua legitimidade para atuar na governança pública circunscreve-se a esse prazo. Os problemas a serem solucionados, no entanto, vão além do período do mandato. Por isso, torna-se necessário um amplo consenso entre a maioria parlamentar e a oposição, para assegurar a continuidade dos trabalhos da rede social e da aliança e para manter unidos os atores participantes ao longo dos diversos períodos legislativos.

t Dessa forma, fica claro que a capacidade dos atores para construir alianças é limitada. As redes sociais e as alianças, em vista de sua dinâmica e funcionamento próprios, pressupõem que todos os parceiros se envolvam em processos de aprendizagem. Nos arranjos de governança pública existe um código de conduta entre os parceiros, que é diferente do preconizado pelos modelos hierárquicos. Os parceiros das redes sociais e alianças, por serem recrutados entre os atores corporativos (como nos arranjos tripartites), serão parceiros em decorrência de sua função na organização a que pertencem. Eles não apenas representam sua organização (por exemplo, o sindicato), mas também precisam mobilizar e convencer os membros dela para o trabalho a ser realizado em cooperação com terceiros. A governança pública não pode ser imposta. Ela se origina de um processo de troca que oscila entre o topo e a base em toda a organização. Por isso, supomos que a nova cultura, propiciada por um reformulado código de conduta dos atores da governança, não se aplica tão-somente à estrutura da governança como tal, mas deve impregnar as próprias organizações participantes. Desse modo, os parceiros, liderando uma coalizão em rede ou uma aliança, irão construir efetivamente as bases para o desenvolvimento de uma confiança mútua.

t A governança pública pressupõe regras de jogo e institucionalização. As duas coisas ainda estão pouco caracterizadas no contexto alemão. Isso transparece no exemplo das alianças municipais de trabalho. Elas se situam entre os extremos da "regulamentação e desregulamentação". Uma forte regulamentação (por exemp- 
lo, por meio de contratos) restringe a capacidade de inovação. Em contrapartida, uma aliança fracamente regulamentada (talvez com objetivos estratégicos precários) pode levar a uma incomunicabilidade entre os parceiros, ou estar sendo fortemente conduzida por simples pessoas, e não por atores investidos em papéis. Quando as pessoas saem, a aliança naufraga. Por isso, sem regras de jogo, o sucesso da governança pública se torna antes “obra do acaso” de pessoas engajadas, mas sem papéis vinculantes. As regras do jogo devem ser negociadas entre os atores; e, quando modeladas em conjunto, elas também podem fortalecer o autocomprometimento.

t Quanto à organização do processo e do controle sobre os resultados, a prática da governança pública até agora tem apresentado sérias deficiências. A organização do processo deveria ser tão descentralizada quanto possível e brindar os atores participantes com autonomia. Além disso, uma coordenação central deveria garantir a troca de informações e a comunicação no processo de governança e, ao mesmo tempo, assegurar ampla transparência sobre as providências e atividades locais desenvolvidas. Essa seria atribuição de uma gestão estratégica. Mas é justamente isso o que ainda falta aos municípios e às regiões. Os controles sobre resultados e as avaliações certamente têm soado, nas últimas décadas, ao lado da modernização administrativa, como a “cantilena da modernização” nas prefeituras alemãs, mas de maneira alguma retratam a práxis da reforma. A reavaliação constante das metas, dos recursos empregados e dos procedimentos é imprescindível. Dependem disso a gestão dos processos de governança pública e seu desenvolvimento subseqüente e, sobretudo, a legitimação de atuação dos atores em relação a sua própria organização.

A pergunta que trata dos reflexos sobre a democracia local é uma das que ainda estão em aberto e não foi respondida até agora pela práxis da governança pública. Da união dos parceiros locais poderia resultar uma impulsão positiva para o fortalecimento da democracia. As chances de democratização das redes e alianças comunitárias residem na inclusão dos grupos-alvo como também dos parceiros do terceiro setor e das forças da sociedade civil; em outras palavras, dependem de uma sociedade reativada, mobilizada. Por isso, a governança pública, o Estado ativador e a sociedade civil são, freqüentemente, mencionados juntos nos debates acadêmicos. A governança pública poderia, assim, representar o terceiro pilar da democracia comunitária, ao lado da democracia representativa (praticada na Alemanha pela eleição dos membros das câmaras de vereadores) e da democracia direta (pela vontade e decisão dos cidadãos). Seu fundamento é a cooperação por meio de alianças e redes políticas. 
Mas, em vista dos problemas descritos e do limitado alcance da capacidade de gestão e de financiamento, deve-se questionar se a força legitimadora dos procedimentos da governança pública seria suficiente para fundamentar essa nova forma de exercício do poder: o "poder do povo" pela cooperação. Essa seria a perspectiva de uma polis, na qual os cidadãos, em conjunto, se preocupariam com a res publica e velariam pelo bom nome das organizações públicas, no sentido de entidades que cuidam do que é público e do que o público significa.

Quanto aos problemas levantados no início e à capacidade limitada da governança pública para resolver problemas, permanece, porém, um certo ceticismo. Aqueles que optarem pela governança pública terão pela frente um caminho longo e árduo. Resta saber se o objetivo maior - a democracia cooperativa - poderá ser atingido ou não.

\section{Referências bibliográficas}

ACHE, P. Visions and creativity: challenge for city regions. Futures, v. 32, n. 5, p. 435-449, June 2000.

ADAMASCHEK, Bernd; PRÖHL, Marga (Orgs.). Regionen erfolgreich steuern. Regional Governance: von der kommunalen zur regionalen Strategie. Gütersloh, 2003.

BOGUMIL, Jörg. Ökonomisierung der Verwaltung. In: CZADA, Roland; ZINTL, Reinhard (Orgs.). Politik und Markt. PVS-Sonderheft 33. Opladen, 2004.

DAMKOWSKI, Wulf; RÖSENER, Anke. Auf dem Weg zum Aktivierenden Staat. Vom Leitbild zum umsetzungsreifen Konzept. Berlin, 2003.

JANN, Werner. Governance. In: EICHHORN, Peter (Org.). Verwaltungslexikon, 3. ed. Aufl. Baden Baden, p. 449-451, 2003.

KISSLER, Leo. Kommunale Arbeitsmarkt- und Beschäftigunspolitik. Genese und Struktur eines neuen Politikfeldes. In: KISSLER, Leo; WIECHMANN, Elke (Orgs.). Die Zukunft der Arbeit in den Städten. Kommunale Bündnisse für Arbeit aus Akteurs- und Forschungssicht. Baden Baden, p. 9-20, 2003.

—; GREIFENSTEIN, Ralph; WIECHMANN, Elke. Kommunale Bündnisse für Arbeit. Neue Perspektiven für die Zukunft der Arbeit in den Städten. Berlin, 2003.

KLENK, T.; NULLMEIER, F. Public Governance als Reformstrategie. Düsseldorf, 2003.

KOOIMAN, J. Social political governance: overview, reflections and design. Public Management: an International Journal of Research and Theory, v. 1, n. 1, p. 67-92, 2000. 
LÖFFLER, Elke. Governance: Die neue Generation von Staats- und Verwaltungs- modernisierung. Verwaltung + Management, v. 7, n. 4, p. 212-215, 2001.

NASCHOLD, Frieder et al. Leistungstiefe im öfflichen Sektor: Erfahrungen, Konzepte und Methoden. Berlin, 1996. 